\title{
Correction to: The Ichnological Record of Araraquara Sidewalks: History, Conservation, and Perspectives from This Urban Paleontological Heritage of Southeastern Brazil
}

\author{
Heitor Francischini ${ }^{1}$ (D) Marcelo Adorna Fernandes ${ }^{2} \cdot$ Josiane Kunzler $^{3} \cdot$ Robson Rodrigues $^{3} \cdot$ Giuseppe Leonardi $^{4}$. \\ Ismar de Souza Carvalho ${ }^{5}$
}

Published online: 22 July 2020

(C) The European Association for Conservation of the Geological Heritage 2020

\section{Correction to: Geoheritage (2020) 12:50 \\ https://doi.org/10.1007/s12371-020-00472-5}

In spite of the correction made by the authors, this paper was published online in its non-corrected proof version. Although the typo and formating errors do not affect the validity of the results and discussion presented, we feel they can be rectified here.

The correct order of the Figs. 4 and 5 was switched. The correct way in which they should appear is provided below.

The online version of the original article can be found at https://doi.org/ 10.1007/s12371-020-00472-5

Heitor Francischini

heitor.francischini@ufrgs.br

Laboratório de Paleontologia de Vertebrados, Instituto de

Geociências, Universidade Federal do Rio Grande do Sul (UFRGS), Porto Alegre, RS, Brazil

2 Laboratório de Paleoecologia e Paleoicnologia, Departamento de Ecologia e Biologia Evolutiva, Universidade Federal de São Carlos (UFSCar), São Carlos, SP, Brazil

3 Fundação Araporã, Araraquara, SP, Brazil

4 Cavanis Institute, Venice, Italy

5 Departamento de Geologia, Instituto de Geociências, Universidade Federal do Rio de Janeiro (UFRJ), Rio de Janeiro, RJ, Brazil 


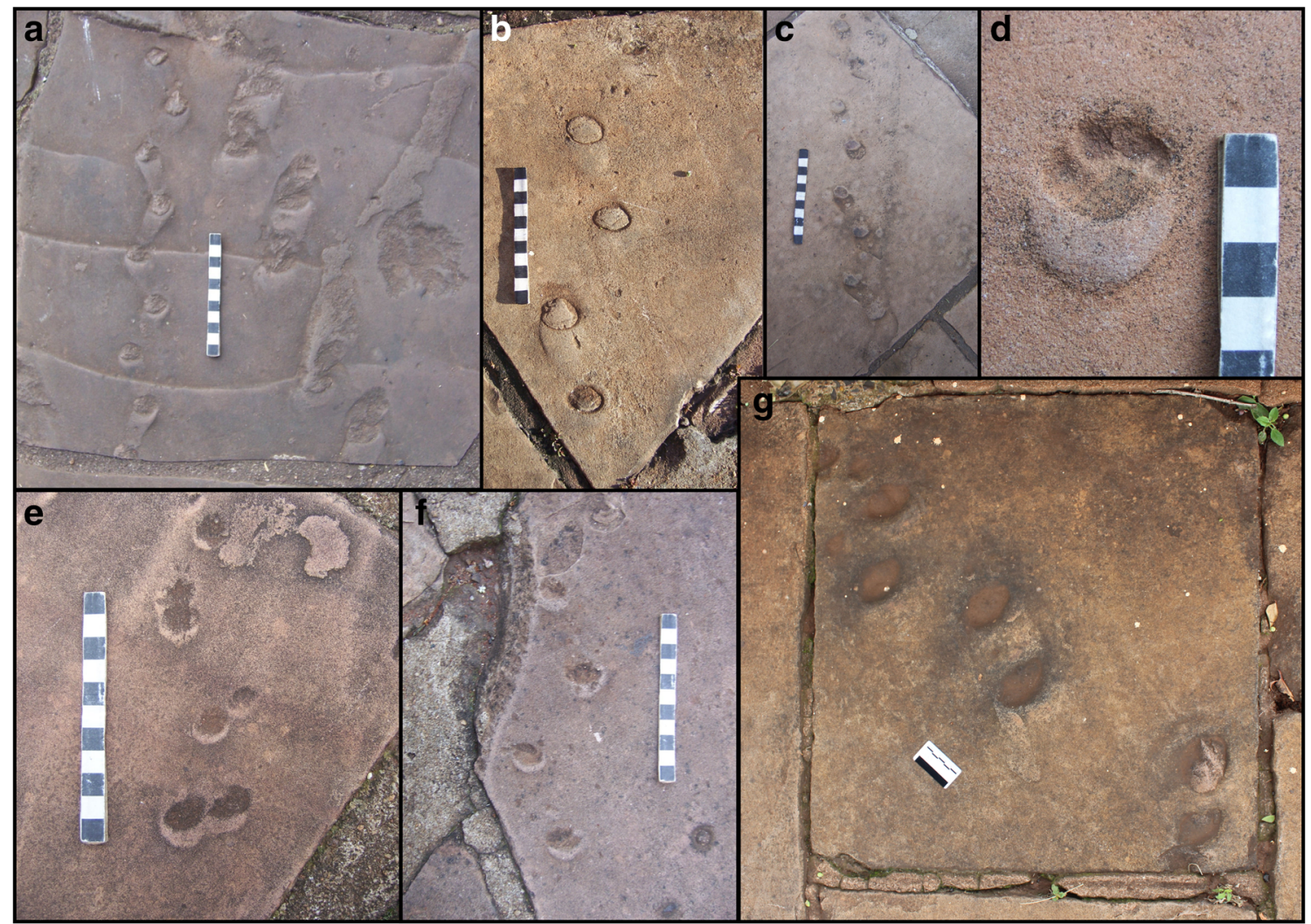

Fig. 4 Mammal tracks (Morphotype 4) found in slabs from the sidewalks of Araraquara, Brazil. Scale bars in centimeters

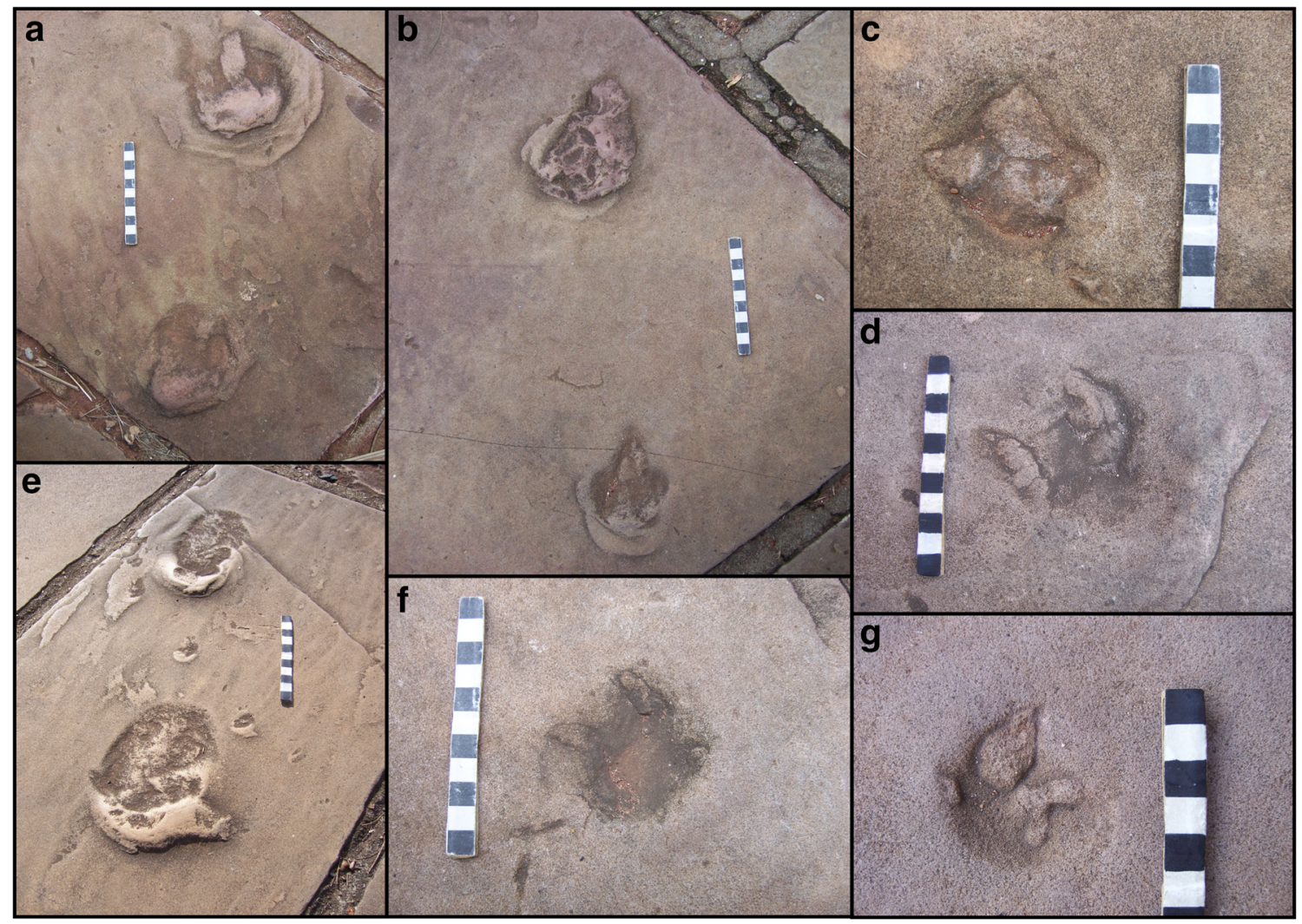

Fig. 5 Dinosaur tracks (Morphotype 5) found in slabs from the sidewalks of Araraquara, Brazil. Scale bars in centimeters 